\title{
Stomach as a source of colonization of the respiratory tract during mechanical ventilation: association with ventilator-associated pneumonia
}

\author{
A. Torres, M. El-Ebiary, N. Soler, C. Montón, N. Fàbregas, C. Hernández
}

\begin{abstract}
Stomach as a source of colonization of the respiratory tract during mechanical ventilation: association with ventilator-associated pneumonia. A. Torres, M. El-Ebiary, N. Soler, C. Montón, N. Fàbregas, C. Hernández. @ERS Journals Ltd 1996.

ABSTRACT: The aetiopathogenesis of ventilator-associated pneumonia (VAP) requires abnormal oropharyngeal and gastric colonization and the further aspiration of their contents to the lower airways. VAP develops easily if aspiration or inoculation of microorganisms occur in patients with artificial airways, in whom mechanical, cellular and/or humoral defences are altered.

Well-known risk factors for gastric colonization include: alterations in gastric juice secretion; alkalinization of gastric contents; administration of enteral nutrition; and the presence of bilirubin. However, the role of the colonized gastric reservoir in the development of VAP remains debatable.

Evidence in favour of the role of the stomach in the development of VAP comes mainly from randomized, controlled trials of selective gut decontamination and stress ulcer prophylaxis in the intensive care unit (ICU), in which reducing the bacterial burden of the stomach decreases the incidence of nosocomial respiratory infections. However, at least three studies of flora have found an absence of stomach origin of pneumonia occurring during mechanical ventilation.

Prophylactic measures suggested to prevent VAP in relation to the gastric reservoir include: treatment for stress ulcers with sucralfate; prevention of duodenal reflux with metoclopramide; reduction of gastric burden and bacterial translocation by selective digestive decontamination; acidification of enteral feeding; and jejunal feeding. Gastro-oesophageal reflux can be prevented by using small bore nasogastric tubes and jejunal feeding. The aspiration of gastric contents can be reduced by positioning patients in a semirecumbent position, checking the patency of the tube cuff, and aspiration of subglottic secretions.

The role of the stomach as a reservoir for microorganisms causing ventilatorassociated pneumonia is still controversial but despite the debate, there is major evidence in the literature in favour of the gastric origin of part of these pulmonary infections.
\end{abstract}

Eur Respir J., 1996, 9, 1729-1735.

Servei de Pneumologia i Al.èrgia Respiratòria, Departament de Medicina, Universitat de Barcelona, Spain.

Correspondence: A. Torres

Servei de Pneumologia

Hospital Clínic

c/Villarroel 170

08036 Barcelona

Spain

Keywords: Gastric colonization

pathogenesis

pneumonia

ventilator-associated pneumonia

Received: July 281995

Accepted for publication March 101996
The understanding of the pathogenesis of ventilatorassociated pneumonia (VAP) has evolved during recent years. The incidence of this common complication of mechanical ventilation ranges 9-70\% [1-3]. The aetiopathogenesis of VAP requires abnormal oropharyngeal and gastric colonization and the further aspiration of their contents to the lower airways $[4,5]$. Nevertheless, recent information, in contrast to other studies, suggests that the stomach is not always a reservoir for colonization [6]. Other sites which can potentially harbour microorganisms involved in the pathogenesis of VAP include gingival plaque and periodontal pockets [7] (fig. 1). Inoculation of colonizing bacteria into the distal airways occurs as contaminated oropharyngeal and/or gastric secretions reach the endotracheal tube and trachea. These contaminated secretions are then propelled to the distal airways by inspiratory airflow from mechanical ventilation or endotracheal tube manipulation. If the host's mechanical, cellular and/or humoral defences are overwhelmed, then bacterial proliferation exceeds bacterial clearance, leading to the development of VAP [8]. An alternative aetiopathogenic mechanism to explain the development of VAP is bacterial translocation, although this mechanism is still under investigation [9].

In the present article, we review the possible role of the stomach in the aetiopathogenesis of VAP, emphasizing the following issues: 1) risk factors for gastric colonization; 2) clinical evidence of gastric aspiration to the lower airways in mechanically-ventilated patients; 3 ) clinical evidence and controversies of the role of the gastric reservoir in ventilator-associated pneumonia; 4) the role of bacterial translocation as a mechanism for the development of VAP; and 5) a summary of prophylactic measures.

\section{Risk factors for gastric colonization}

The stomach has been postulated to be an important reservoir of organisms that cause VAP $[10,11]$. The 


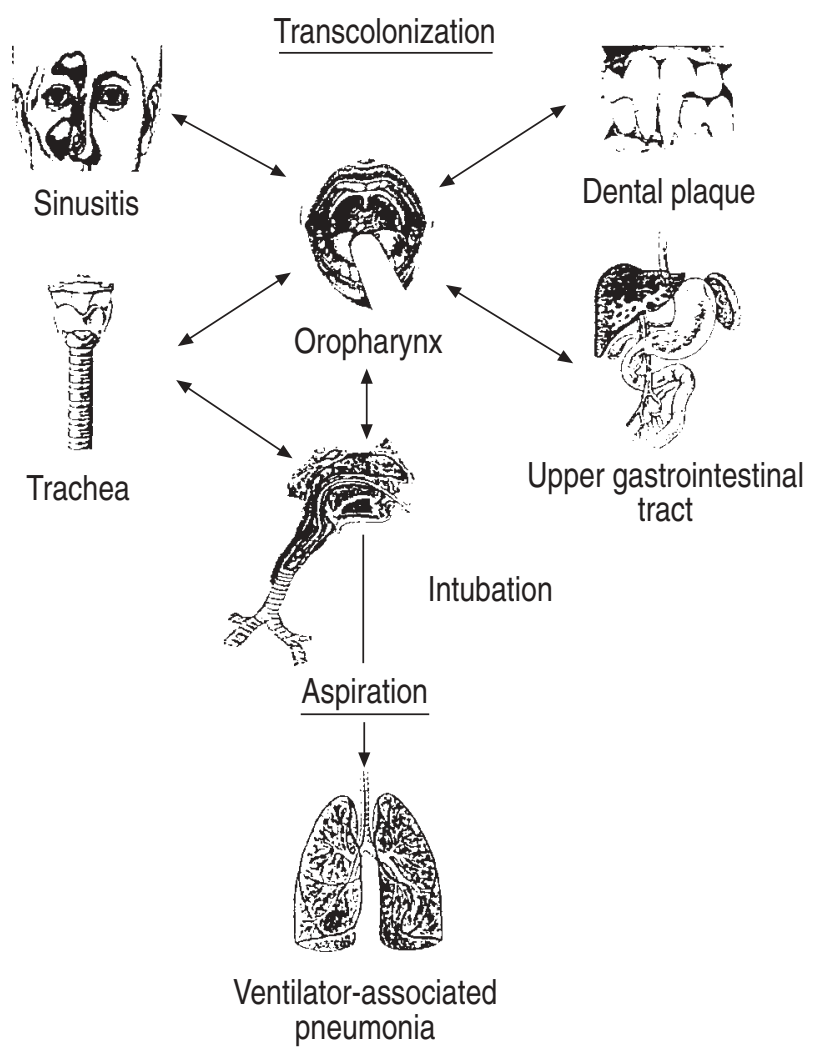

Fig. 1. - Pathogenesis of ventilator-associated pneumonia: the colonization of sinuses, dental plaque, oropharynx, upper airways, and the gastrointestinal tract play a pivotal role in the development of ventilator-associated pneumonia. (Reprinted with permission from [7]).

stomach's role may vary depending on the patient's underlying condition and on prophylactic or therapeutic interventions. In healthy persons, few bacteria entering the stomach survive in the presence of hydrochloric acid at $\mathrm{pH}<2$. The potent bactericidal activity of hydrochloric acid in gastric secretions was first demonstrated by GARROD [12].

There are four well-known risk factors for gastric colonization: 1) alterations in secretion of gastric juice; 2) alkalinization of gastric contents; 3) administration of enteral nutrition, and 4) the presence of bilirubin. When gastric $\mathrm{pH}$ increases from the normal levels to $\geq 4$, microorganisms are able to multiply to high concentrations in the stomach. This can occur in patients with advanced age, malnutrition, achlorhydria, ileus, or upper gastrointestinal diseases [5]. Alkalinization of gastric contents in the critically ill patient may result from the intrinsic decrease of gastric acid production or from the use of antacids or histamine type $2\left(\mathrm{H}_{2}\right)$ antagonists, which neutralize or block secretion of gastric acid. Du Moulin et al. [13] and DonowiTz et al. [14] were among the first authors to demonstrate the relationship between alkalinization of gastric contents and overgrowth of bacteria.

Figure 2 shows the correlation between gastric $\mathrm{pH}$ and concentrations of Gram-negative bacilli in the gastric contents from critical care patients receiving antacids $(\mathrm{r}=0.4 ; \mathrm{p}<0.001)$. Several other authors have demonstrated this relationship [5]. A recent work by PROD'HOM et al. [15] clearly confirms that decreasing gastric $\mathrm{pH}$ by use of sucralfate (mean $\mathrm{pH} 4.30$ ) decreases gastric colonization when compared to antacids (mean $\mathrm{pH} 7.10$ ) or

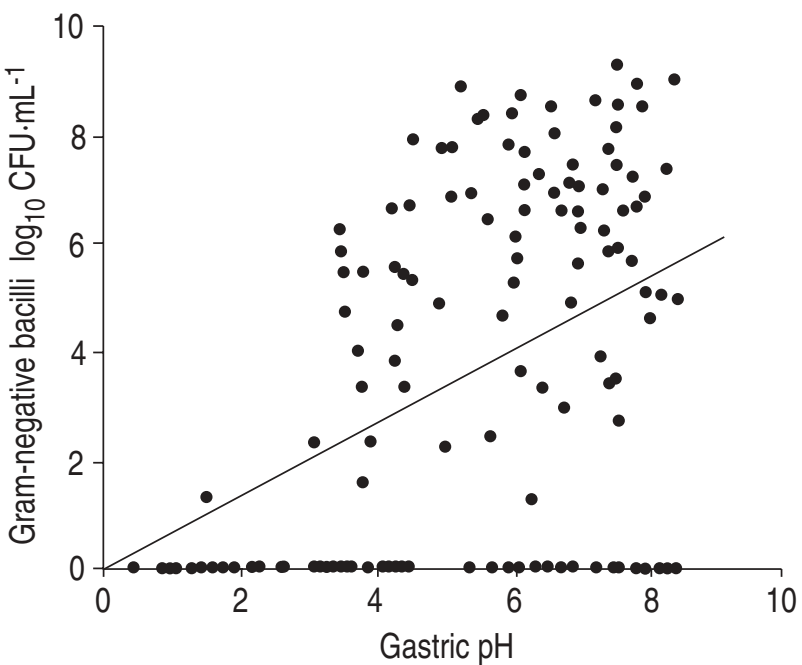

Fig. 2. - Correlation between gastric $\mathrm{pH}$ and concentrations of Gramnegative bacilli (colony-forming units $(\mathrm{CFU}) \cdot \mathrm{mL}^{-1}$ ) of gastric contents from critical care patients receiving antacids $(\mathrm{r}=0.4 ; \mathrm{p}<0.001)$. (Reprinted with permission from [13]).

ranitidine (mean $\mathrm{pH}$ 6.27). Therefore, the relationship between gastric $\mathrm{pH}$ and overgrowth of gastric bacteria seems clear. However, it is important to note that indications for stress ulcer prophylaxis have been restricted to patients with alterations in coagulation disorders or who need mechanical ventilation [16]. An interesting alternative explanation for overgrowth of Gram-negative bacilli in the gastric contents could be the increase in gingival and periodontal presence of these microorganisms, which contaminate saliva [6]. This contaminated saliva is swallowed into a more favourable gastric environment, allowing bacterial proliferation and successful gastric colonization.

Enteral nutrition is the usual way to feed critically ill patients. Nutrients administered via a nasogastric tube (NGT) have a relatively high $\mathrm{pH}$, and for that reason may modify gastric $\mathrm{pH}$ and promote gastric colonization. Pingleton et al. [17] demonstrated gastric colonization in $100 \%$ of 18 ventilated patients receiving enteral nutrition without antacid or $\mathrm{H}_{2}$ blockers. Sixty three percent of the patients developed nosocomial pneumonia. Some authors have tried to modify the negative effects of enteral nutrition on gastric $\mathrm{pH}$. For instance, Heyland et al. [18] decreased the rate of gastric colonization by giving acidified enteral nutrition. MonTECALvo et al. [19] achieved a lesser degree of gastric bacterial overgrowth by feeding through an endoscopically placed jejunal tube. These two clinical trials confirm the relationship between enteral diet and alkalinization of gastric $\mathrm{pH}$.

INGLIS et al. [20] demonstrated that the presence of bilirubin $\left(>10 \mathrm{mg} \cdot \mathrm{L}^{-1}\right)$ in gastric aspirates is the most important factor related to the presence of Gram-negative bacilli in gastric juice. The presence of bilirubin in gastric contents must be explained by a decreased duodenal motility, and for that reason pharmacological interventions directed to increasing gastric and duodenal motility could be of prophylactic interest. The model proposed by these authors consisted of retrograde colonization, in which impaired gastric and small intestinal motility permit bacterial overgrowth in the duodenum. Gram-negative bacilli are then transferred to the stomach by gastroduodenal reflux, and increase in number due to a high 
intragastric $\mathrm{pH}$. Gram-negative bacilli are then regurgitated in stomach contents via the oesophagus, and finally aspirated into the trachea.

\section{Clinical evidence for gastric aspiration to the lower airways}

Direct and indirect evidence exists in the medical literature indicating that gastric contents can be aspirated into the lower airways despite the apparent patency of an endotracheal tube cuff. At least two publications [21, 22] have found frequent presence of glucose in endotracheal secretions, indicating aspiration of enteral feeding. However, this method has been seriously questioned by KINSEY et al. [23], since they suggested that the concentration of glucose in tracheal secretions appears to be determined, in part, by ambient extracellular glucose concentrations. These authors concluded that measurement of glucose in tracheal secretions is unlikely to be useful in monitoring tube feeding aspiration in tracheally-intubated, enterally fed patients.

By labelling the gastric contents with technetium sulphur colloid and studying patients in two positions (semirecumbent and supine), we detected radioactivity counts - in a time-dependent pattern - in the bronchial secretions, indicating pulmonary aspiration of gastric contents. A great percentage of aspiration could be prevented in the supine position [24]. In a further study using the same methodology, we reproduced this model but observed

a)

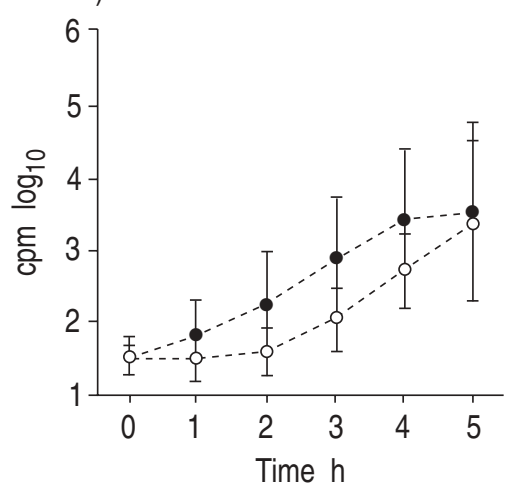

c)

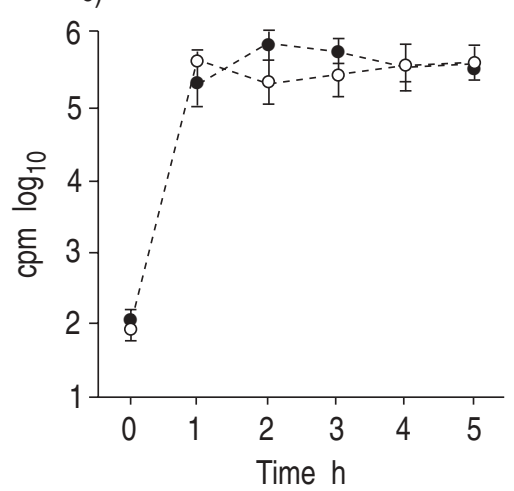

that body position did not influence gastro-oesophageal reflux measured by the presence of radioactivity in the oropharynx [25] (fig. 3). Consequently, although supine position is crucial in preventing gastric aspiration to the lower airways, this manoeuvre is only partially efficacious in the prophylaxis of retrograde oropharyngeal colonization from the stomach. Other studies have found similar results [26]. A recent study from our group [27] showed that in $61 \%$ of the pneumonia episodes in reintubated patients, the causal microorganism was previously isolated from either the oropharynx or the stomach. Moreover, the authors suggest that in reintubated patients the risk of gastric aspiration increases, particularly if a nasogastric tube is kept in place after extubation.

In summary, all these studies show that in mechanically-ventilated patients with a nasogastric tube in place, there is gastro-oesophageal reflux and aspiration of stomach contents to lower airways.

\section{Evidence and controversies regarding the role of a gastric reservoir in development of VAP}

\section{Evidence in favour}

Garvey et al. [28], studying gastric and oropharyngeal flora, found that tracheobronchial colonization was preceded by gastric colonization in 12 out of 25 critically ill patients. Similarly, APTE et al. [29] found a gastric origin in around $50 \%$ of 31 patients with VAP. Our
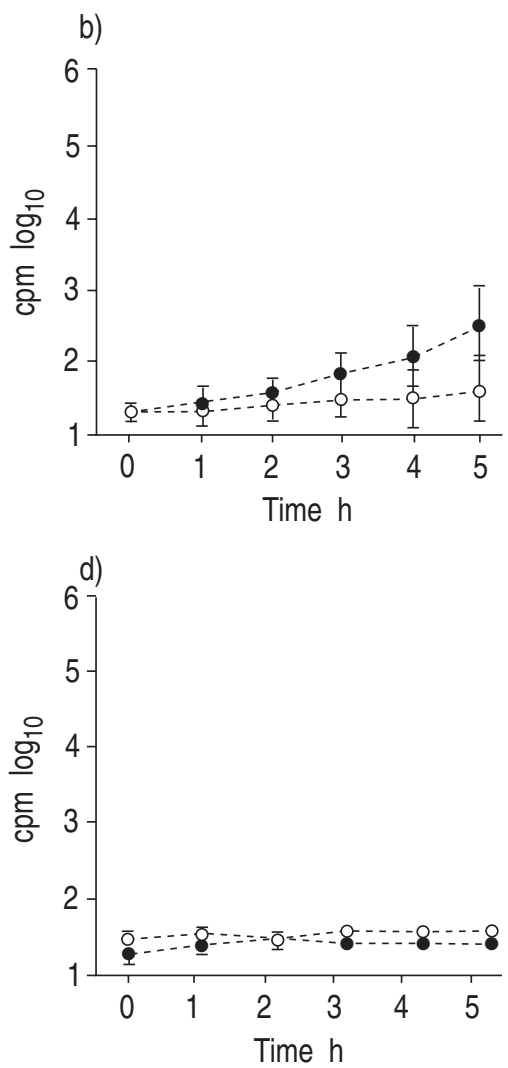

Fig. 3. - Scintigraphic radioactivity counts sequentially recovered (from 0-5 h) from: a) oropharyngeal; b) bronchial; c) gastric; and d) blood samples, expressed in counts per minute $(\mathrm{cpm})\left(\log _{10}\right)$ in each position. ------ : supine; ------- : semirecumbency. Data are presented as mean \pm SEM. Notice that during semirecumbency there is a decrease in radioactivity counts measured in bronchial secretions in comparison to supine (panel b). However, semirecumbency could not prevent gastroesophageal reflux as measured in pharyngeal secretions (panel a). (Reprinted with permission from [25]). 
group studied the bacterial flora of gastric, pharyngeal, bronchial and distal airways samples in patients with and without pneumonia. In patients with pneumonia, the coincidence between gastric and distal airways samples increased threefold compared to patients without pneumonia, indicating the possible gastric origin of nosocomially-acquired pneumonia [30]. In a review article attempting to ascertain the association between gastric colonization and nosocomial pneumonia, HEYLAND and MANDELl [31] found a positive relationship. The strongest evidence came from randomized, controlled trials of selective gut decontamination and stress ulcer prophylaxis in intensive care units (ICUs) [32], in which reducing the bacterial burden of the stomach decreased the incidence of nosocomial respiratory infections. INGLIS et al. [20] sequentially studying gastric and tracheal bacterial flora in mechanically-ventilated patients, found that microorganisms isolated from tracheal aspirates were always previously isolated in gastric juice samples (fig. 4). Finally, a recent study by PROD'HOM et al. [15] demonstrated a reduced incidence of VAP $(5 \%)$ in patients receiving sucralfate (a drug which does not markedly increase gastric $\mathrm{pH}$ ) compared to 16 and $21 \%$ rates of incidence in patients receiving antacids or ranitidine, respectively. Using molecular typing, $84 \%$ of the patients with late-onset Gram-negative bacillary pneumonia were found to have gastric colonization with the same bacteria before pneumonia developed.

In addition to these works, which have found a bacteriological pattern of transmission between the stomach and airways, there are several studies of risk factors for VAP, which have found some degree of relationship between the stomach and the development of nosocomial pulmonary infection. For instance, Celis et al. [33], and Joshi et al. [34] have demonstrated that the presence of a nasogastric tube is a risk factor for the development of VAP, indicating the importance of gastro-oesophageal reflux. Other authors $[33,35]$ have found a clear association between pulmonary aspiration of gastric contents and VAP. Finally, KolLEF [36], in a multivariate analysis of risk factors, demonstrated that supine position (a

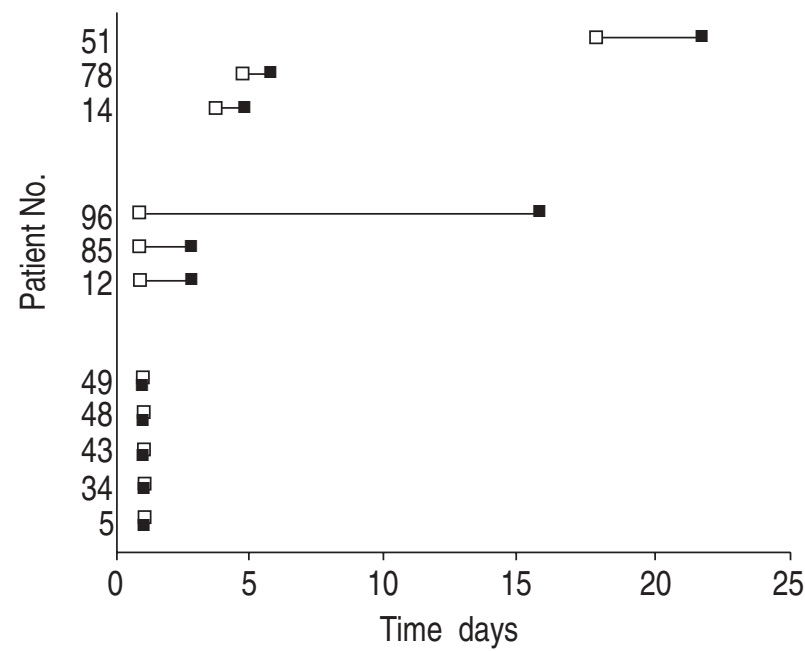

Fig. 4. - Acquisition of Gram-negative bacilli in upper airways and stomach from mechanically-ventilated patients. Notice that Gram-negative bacilli were always isolated from the stomach on the first occasion. $\square$ : time of first isolation in gastric aspirate; $\mathbf{\square}$ : time of first isolation in tracheal aspirate. (Reprinted with permission from [20]). risk factor for pulmonary aspiration of gastric contents) during the first $24 \mathrm{~h}$ of mechanical ventilation is an independent risk factor for acquisition of VAP.

\section{Evidence against}

Despite all these arguments in favour of the role of a gastric reservoir in the development of VAP, several studies have shown the opposite results. At least four studies of flora have found an absence [6, 37-39] of stomach origin of pneumonia originating during mechanical ventilation. These studies were performed in respiratory, trauma, neurosurgical, and mixed ICU populations. For instance, REusser et al. [38] examined the role of gastric microbial colonization and endotoxaemia in the genesis of VAP in 40 neurosurgical patients requiring mechanical ventilation for more than $48 \mathrm{~h}$. Nosocomial pneumonia occurred in 15 patients, septicaemia in five, and meningitis in one. The stomach was the evident source of infection in only one patient with pneumonia. Of 140 serum samples, 12 (9\%) from 10 patients showed detectable endotoxin levels, but there was no association between endotoxaemia or coagulation activation and the presence of microorganisms in the stomach. BONTEN et al. [39] studied sequences of colonization of different species of microorganisms in 59 intubated patients who developed 14 episodes of pneumonia, and could not find a sequence of colonization from the stomach to the upper airways in those patients. In addition, initial colonization with Pseudomonas aeruginosa and Enterobacter spp. was more often demonstrated in the trachea as compared with the stomach. These authors, in another study [40], significantly reduced colonization of the oropharynx and trachea by using topical antimicrobial prophylaxis.

Two further studies [41, 42] from the same group, administered selective oropharyngeal antibiotics, without gastric decontamination, to prevent nosocomial pneumonia in mechanically-ventilated patients, and could find no association between the gastric colonization and the aetiological causative agents of the pulmonary infections. They concluded that nosocomial pneumonia could be prevented by the local application of nonabsorbable antibiotics to the oropharynx and, subsequently, that the gastric reservoir does not play any role in VAP.

CoOK et al. [43] examined the differential effect of drugs used for stress ulcer prophylaxis on nosocomial pneumonia by reviewing 48 randomized controlled trials in a meta-analysis. They found 1,198 eligible patients for their analysis, concluding that stress ulcer prophylaxis with drugs which raise gastric $\mathrm{pH}$ does not increase the incidence of pneumonia in comparison to placebo or control therapy. These results, according to the authors, suggest that perhaps alkalinization of gastric contents it is not a crucial factor in the aetiopathogenesis of VAP.

Finally, in a review article by Simms [44], the role of the gastric reservoir and the role of gastric $\mathrm{pH}$ have again been seriously questioned. In particular, the article from PROD'HOM et al. [15] has been more rigorously evaluated in terms of the incidence of pneumonia. This article shows that when analysing only those patients with a gastric $\mathrm{pH}$ higher than 4, the incidence of late-onset pneumonia was not statistically different among the treatment groups, sucralfate, antacids and ranitidine. 


\section{Is bacterial translocation an aetiopathogenic mechanism of VAP?}

For the past decade, clinical and basic scientists have been exploring the hypothesis that the gastrointestinal tract plays a central role in the pathogenesis of multiple organ dysfunction caused by critical illness. The gut hypothesis for multiple organ dysfunction starts with the premise that an important function of the gastrointestinal tract is to serve as a barrier, limiting the systemic absorption of intraluminal microbes and toxins. The gut hypothesis for multiple organ dysfunction then proposes that the barrier function of the gastrointestinal tract is altered in critically ill patients. A potential consequence of deranged barrier function is bloodstream invasion by gut-derived pathogens, leading to primary bacteraemia, or fungaemia, or even metastatic infections [45].

The alteration of the gastric mucosa can be indirectly measured by tonometry, measuring the carbon dioxide tension $\left(\mathrm{PCO}_{2}\right)$ of saline introduced into a balloon catheter inserted in the stomach cavity. Consequently, gastric $\mathrm{pH}$ can be calculated using the Henderson-Hasselbach equation. It has been confirmed that an intramucosal gastric $\mathrm{pH}(\mathrm{pHi})$ below 7.32 is representative of gastric ischaemia and can lead to bacterial translocation. FidDIAN-GreEN and BAKER [9] retrospectively studied intramucosal gastric $\mathrm{pH}$ in 54 critically ill patients, finding that in those with certain, probable, or possible pneumonia, $\mathrm{pHi}$ was significantly lower (7.13-7.20) compared to patients without pneumonia (7.36). Furthermore, in a multivariate analysis of risk factors for the development of VAP, they found that the best stand-alone predictors for nosocomial pneumonia were bleeding from stress ulceration, the severity of illness, and intramucosal acidosis in the stomach. Possible criticisms of these work were that it is impossible to know from the study whether intramucosal gastric acidosis was the cause or the consequence of VAP. Furthermore, the study was performed retrospectively, and there is no clear explanation for the diagnostic methods employed to diagnose pneumonia.

Other authors [38] did not find an association between the presence of microorganisms in the stomach and endotoxaemia or activation of coagulation disorders. We have performed a prospective study [46] on 14 patients with pneumonia and 15 controls, who were haemodynamically stable and did not receive vasoactive drugs, to determine the role of gastric intramucosal $\mathrm{pH}$. The study was observational and performed after the clinical diagnosis of pneumonia has been established; the latter was microbiologically confirmed. The mean $\mathrm{pHi}$ for pneumonia patients was 7.40 versus 7.46 for control patients (NS). However, there were $42 \%$ pneumonia episodes in which pHi measurement was lower than 7.32. Again, we do not know whether this was a cause or consequence, but can say, at least, that $58 \%$ of patients with pneumonia did not have intramucosal gastric acidosis. Sequential studies of pHi gastric measurements are warranted to elucidate bacterial translocation as an alternative mechanism for development of VAP.

\section{Prophylactic measures in relation to the gastric reservoir}

Although this is not the purpose of the present review, we will summarize in this article some well-recognized prophylactic measures to avoid gastric colonization, gastro-oesophageal reflux and gastric aspiration, and perhaps bacterial translocation.

\section{Gastric colonization}

The first logical measure is trying to avoid alkaline gastric $\mathrm{pH}$. Sucralfate is a drug which effectively prevents stress ulceration in critically ill patients without markedly increasing gastric $\mathrm{pH}$. The effects of sucralfate on reducing the incidence of VAP have been highly controversial. A meta-analysis by $\mathrm{COOK}$ et al. [43] concluded that the use of sucralfate is associated with a lower incidence of pneumonia in comparison with drugs which raise gastric $\mathrm{pH}$, although they pointed out the importance of performing further prospective, controlled, randomized trials. A similar conclusion regarding the beneficial effect of sucralfate was obtained by TRYBA [47] in a metaanalysis. A recent study by PROD'HOM et al. [15] has confirmed these conclusions. However, the mechanism of action of sucralfate is not clear and some have invoked the antibacterial effects of this agent [48]. Our policy is to give sucralfate to critically ill patients, since the cost of this agent is similar to antacids or $\mathrm{H}_{2}$ blockers. Other measures, such as administration of acidified diets or jejunal feeding, that could be recommended and seem to decrease gastric $\mathrm{pH}$, have not been extensively investigated and, hence, cannot yet be routinely applied [18, 19].

An interesting measure suggested in the paper by INGLIS et al. [20] would be the administration of agents which increase duodenal motility in order to avoid a retrograde presence of conjugated bilirubin in the stomach. There are still no published trials that confirm this prophylactic measure, although it has been routinely applied for other reasons in many units.

Selective digestive decontamination (SDD) by the administration of several antibiotics into the stomach cavity has been a controversial prophylactic measure for many years. The majority of SDD trials have demonstrated $[32,36]$ a reduction of the bacterial burden of gastric contents and of the incidence of respiratory infections acquired during mechanical ventilation. However, some double-blind trials [49-52] did not confirm these findings, particularly regarding late-onset pneumonia, although in these trials the rate of exogenous pneumonia was not reported. Furthermore, there is no clear, demonstration of beneficial effects of SDD on mortality. Since the cost-effectiveness of this prophylactic measure is not clear we cannot routinely recommend this measure to prevent secondary pulmonary infections originated from the stomach reservoir. However, in young trauma patients and in other specific subpopulations, full selective digestive decontamination regimens, including intravenous cefotaxime, could be recommended. Unpublished information regarding a meta-analysis of individual data from randomized trials suggests that SDD could reduce mortality rate in VAP in the subset of population receiving topical plus systemic antibiotics and scoring an initial Simplified Acute Physiological Score (SAPS) of $10-14$

\section{Bacterial translocation}

If bacterial translocation does infact play a role in the aetiopathogenesis of VAP, the latter could be prevented 
Table 1. - Risk factor and recommended prophylactic measures to prevent VAP in relation to gastric reservoir

\begin{tabular}{|c|c|}
\hline Risk factor & Intervention \\
\hline Alkalinization & $\begin{array}{l}\text { Sucralfate, acidification of enteral } \\
\text { feeding, avoid antacids/H-2 blockers }\end{array}$ \\
\hline Duodenal reflux & Metoclopramide, jejunal feeding \\
\hline Gastric colonization & $\begin{array}{l}\text { SDD, acidification of enteral } \\
\text { feeding, jejunal feeding }\end{array}$ \\
\hline Bacterial translocation & $\begin{array}{l}\text { SDD (?), early treatment of } \\
\text { haemodynamic instability }\end{array}$ \\
\hline $\begin{array}{l}\text { Gastro-oesophageal } \\
\text { reflux }\end{array}$ & Small bore NGT, jejunal feeding \\
\hline $\begin{array}{l}\text { Aspiration of gastric } \\
\text { contents }\end{array}$ & $\begin{array}{l}\text { Semirecumbent position }\left(45^{\circ}\right) \text {, } \\
\text { patency of tube cuff, aspiration of } \\
\text { subglottic secretions. }\end{array}$ \\
\hline
\end{tabular}

VAP: ventilator-associated pneumonia; SDD: selective digestive decontamination; NGT: nasogastric tube.

by gastric decontamination. MARTinez-Pellús et al. [53] demonstrated a decrease in blood levels of endotoxaemia in patients undergoing cardiac surgery (a model representing ischaemia-reperfusion) when administering full SDD regimens, including intravenous cefotaxime. Further studies are needed to prove the efficacy of gut decontamination to prevent VAP related to bacterial translocation.

\section{Gastro-oesophageal reflux and aspiration}

The possible aspiration of gastric contents to the lower airways is first related to the presence of gastro-oesophageal reflux. As demonstrated by our group, gastro-oesophageal reflux is a very common phenomenon in mechanicallyventilated patients and is probably due to the presence of nasogastric tubes [25]. Reducing the bore of nasogastric tubes could be a prophylactic measure to reduce gastro-oesophageal reflux. Semirecumbent body position is an imperative policy in mechanically-ventilated patients to reduce pulmonary aspiration of gastric contents. This measure seems, in addition, to reduce the incidence and mortality of VAP [36]. Finally, all the measures out of the scope of this chapter focusing on the prevention of aspiration are measures that will prevent aspiration of gastric contents. Of particular interest is the use of endotracheal tubes with a double lumen, which prevent the aspiration of secretions pooled above the tube cuff [54, 55]. Table 1 shows a list summarizing the prophylactic measures for VAP in relation to the gastric reservoir.

In conclusion, despite the controversies regarding the role of the stomach as a reservoir for microorganisms causing ventilator-associated pneumonia, there is major evidence in the literature in favour of the gastric origin of part of these pulmonary infections. The role of bacterial translocation has still to be ascertained.

\section{References}

1. Fagon JY, Chastre J, Hance AJ, et al. Detection of nosocomial lung infection in ventilated patients: use of a protected specimen brush and quantitative culture techniques in 147 patients. Am Rev Respir Dis 1988; 138: 110-116.

2. Andrews CP, Coalson JJ, Smith JD, et al. Diagnosis of nosocomial pneumonia in acute diffuse lung injury. Chest 1981; 80: 254-258.

3. Chevret S, Hemmer M, Carlet J, Langer M, and the European Co-operative Group on nosocomial pneumonia. Incidence and risk factors of pneumonia in intensive care units: results from a multicenter prospective study on 996 patients. Intensive Care Med 1993; 19: 256-264.

4. Johanson WG Jr, Pierce AK, Sanford JP, Thomas GD. Nosocomial respiratory infections with Gram-negative bacilli: the significance of colonization of the respiratory tract. Ann Intern Med 1972; 77: 701-706.

5. Craven DE, Daschner FD. Nosocomial pneumonia in the intubated patient: role of gastric colonization. Eur J Clin Microbiol Infect Dis 1989; 8: 40-50.

6. Palmer LB, Donelan SV, Fox G, Bellemore E, Greene WH. Gastric flora in chronically mechanically-ventilated patients. Am J Respir Crit Care Med 1995; 151: 1063-1067.

7. Estes RJ, Meduri GU. The pathogenesis of ventilatorassociated pneumonia. I. Mechanisms of bacterial transcolonization and airway inoculation. Intensive Care Med 1995; 21: 365-383.

8. Cassiere HA, Niederman MS. New etiopathogenic concepts of ventilator-associated pneumonia. Semin Respir Infect 1996; 11: 13-23.

9. Fiddian Green RG, Baker S. Nosocomial pneumonia in the critically ill: product of aspiration or translocation? Crit Care Med 1991; 19: 763-769.

10. Bernhardt H, Knoke M. Recent studies on the microbial ecology of the upper gastrointestinal tract. Infection 1989; 17: 259-263.

11. Knoke M, Bernhardt H. The impact of microbial ecology on clinical problems. Infection 1989; 17: 255-258.

12. Garrod LP. A study of the bacterial power of hydrochloric acid and of gastric juice. St. Bartholomew's Hospital Reports 1939; 72: 145-167.

13. Du Moulin GC, Hedley-White J, Paterson DG, Lisbon A. Aspiration of gastric bacteria in antacid-treated patients: a frequent cause of postoperative colonization of the airway. Lancet 1982; i: 242-245.

14. Donowitz LG, Page MC, Mileur GL, Guenter SH. Alteration of normal gastric flora in critical care patients receiving antacid and cimetidine therapy. Infect Control 1986; 7: 23-26.

15. Prod'hom G, Leuenberger P, Koerfer J, et al. Nosocomial pneumonia in mechanically-ventilated patients receiving antacid, ranitidine, or sucralfate as prophylaxis for stress ulcer: a randomized controlled trial. Ann Intern Med 1994; 120: 653-662.

16. Cook DJ, Fuller HD, Guyatt GH, et al. Risk factors for gastrointestinal bleeding in critically ill patients. N Engl J Med 1994; 330: 377-381.

17. Pingleton SK, Hinthorn DR, Liu C. Enteral nutrition in patients receiving mechanical ventilation: multiple sources of tracheal colonization include the stomach. Am J Med 1986; 80: 827-832.

18. Heyland D, Bradley C, Mandell LA. Effect of acidified enteral feedings on gastric colonization in the critically ill patient. Crit Care Med 1992; 20 (10): 1388-1394.

19. Montecalvo MA, Steger KA, Farber HW, et al. Nutritional outcome and pneumonia in critical care patients randomized to gastric versus jejunal tube feedings. Crit Care Med 1992; 20: 1377-1387.

20. Inglis TJ, Sherrat MJ, Sproat LJ, Gibson JS, Hawkey PM. Gastroduodenal dysfunction and bacterial colonisation of the ventilated lung. Lancet 1993; 341: 911-913.

21. Winterbauer RH, Durning RB, Barron E, McFadden MC. 
Aspirated nasogastric feeding solution detected by glucose strips. Ann Intern Med 1981; 95: 67-68.

22. Potts RG, Zaroukian MH, Guerrero PA, Baker CD. Comparison of blue dye and glucose oxidase test strip methods for detecting pulmonary aspiration of enteral feeding in intubated adults. Chest 1993; 103: 117-121.

23. Kinsey GC, Murray MJ, Swensen SJ, Miles JM. Glucose content of tracheal aspirates: implications for the detection of tube feeding aspiration. Crit Care Med 1994; 22: $1557-1562$.

24. Torres A, Serra-Batlles J, Ros E, et al. Pulmonary aspiration of gastric contents in patients receiving mechanical ventilation: the effect of body position. Ann Intern Med 1992; 116: 540-543.

25. Orozco-Levi M, Torres A, Ferrer M, et al. Semirecumbent position protects from pulmonary aspiration but not completely from gastroesophageal reflux in mechanicallyventilated patients. Am J Respir Crit Care Med 1995; $1387-1390$.

26. Ibañez J, Peñafiel A, Raurich JM, Marse P, Jordá R, Mata F. Gastroesophageal reflux in intubated patients receiving enteral nutrition: effect of supine and semirecumbent positions. J Parent Enteral Nutr 1992; 16: 419-422.

27. Torres A, Gatell JM, Aznar E, et al. Reintubation increases the risk of nosocomial pneumonia in patients needing mechanical ventilation. Am J Respir Crit Care Med 1995; 152: 137-141.

28. Garvey BM, McCambley JA, Tuxen DV. Effects of gastric alkalization on bacterial colonization in critically ill patients. Crit Care Med 1989; 17: 211-216.

29. Apte NM, Karnad DR, Medhekar TP, Tilve GH, Morye $\mathrm{S}$, Bhave GG. Gastric colonization and pneumonia in intubated critically ill patients receiving stress ulcer prophylaxis: a randomized, controlled trial. Crit Care Med 1992; 20: 590-593.

30. Torres A, El-Ebiary M, Gonzalez J, et al. Gastric and pharyngeal flora in nosocomial pneumonia acquired during mechanical ventilation. Am Rev Respir Dis 1993; 148: $352-357$.

31. Heyland D, Mandell LA. Gastric colonization by Gramnegative bacilli and nosocomial pneumonia in the intensive care unit patients: evidence for causation. Chest 1992; 101: 187-193.

32. Selective Decontamination of the Digestive Tract Trialists' Collaborative Group. Meta-analysis of randomized controlled trials of selective decontamination of the digestive tract. BMJ 1993; 307: 525-532.

33. Celis R, Torres A, Gatell JM, Almela M, RodríguezRoisin R, Agustí Vidal A. Nosocomial pneumonia: a multivariate analysis of risk and prognosis. Chest 1988; 93: $318-324$.

34. Joshi N, Localio R, Hamory BH. A predictive risk index for nosocomial pneumonia in the intensive care unit. Am J Med 1992; 93: 135-142.

35. Torres A, Aznar R, Gatell JM, et al. Incidence, risk and prognosis factors of nosocomial pneumonia in mechanically-ventilated patients. Am Rev Respir Dis 1990; 142: 523-528.

36. Kollef MH. Ventilator-associated pneumonia: a multivariate analysis. JAMA 1993; 270: 1965-1970.

37. Simms HH, DeMaria E, McDonald L, Peterson D, Robinson A, Burchard KW. Role of gastric colonization in the development of pneumonia in critically ill trauma patients: results of prospective randomized trial. J Trauma 1991; 31: 531-536.

38. Reusser P, Zimmerli W, Scheidegger D, Marbet GA,
Buser M, Klaus G. Role of gastric colonization in nosocomial infections and endotoxemia: a prospective study in neurosurgical patients on mechanical ventilation. $J$ Infect Dis 1989; 160: 414-421.

39. Bonten M, Gaillard CA, vanTiel FH, Smeets HG, Geest $\mathrm{SV}$, Stobberingh EE. The stomach is not a source for colonization of the upper respiratory tract and pneumonia in ICU patients. Chest 1994; 105: 878-884.

40. Bonten M, Gaillard CA, Johanson WG, et al. Colonization in patients receiving and not receiving topical antimicrobial prophylaxis. Am J Respir Crit Care Med 1994; 150: 1332-1340.

41. Martinez-Pellús AE, Ruiz J, Garcia J, et al. Role of selective digestive decontamination (SDD) in the prevention of nosocomial pneumonia (NP): is gastric decontamination necessary? Intensive Care Med 1992; 18: 218-221.

42. Rodriguez-Roldan JM, Altuna-Cuesta A, Lopez A, et al. Prevention of nosocomial lung infection in ventilated patients: use of an antimicrobial pharyngeal nonabsorbable paste. Crit Care Med 1990; 18: 1239-1242.

43. Cook D, Laine LA, Guyatt GH, Raffin TA. Nosocomial pneumonia and the role of gastric $\mathrm{pH}$ : a meta-analysis. Chest 1991; 100: 7-13.

44. Simms HH. Gastric alkalinization does not increase the risk of pneumonia in critically ill patients. Semin Respir Infect 1994; 9: 222-227.

45. Fink MP. Role of the gut in the pathogenesis of septic complications in critical illness. Semin Respir Infect 1994; 9: 221.

46. El-Ebiary M, Torres A, Hernandez C, et al. Is bacterial translocation an etiopathogenic mechanism in the development of nosocomial pneumonia? Am J Respir Crit Care Dis 1994; 149: A972.

47. Tryba M. Sucralfate versus antacids or $\mathrm{H}_{2}$-antagonists for stress ulcer prophylaxis: a meta-analysis on efficacy and pneumonia rate. Crit Care Med 1991; 19: 942-949.

48. Tryba M, Mantey-Stiers F. Antibacterial activity of sucralfate in human gastric juice. Am J Med 1987; 83 (Suppl. 3B): 125-127.

49. Ferrer M, Torres A, Gonzalez J, et al. Utility of selective digestive decontamination in mechanically-ventilated patients. Ann Intern Med 1994; 120: 389-395.

50. Hammond JM, Potgieter PD, Saunders GL, Forder AA. Double-blind study of selective decontamination of the digestive tract in intensive care. Lancet 1992; 340: 5-9.

51. Hammond JM, Potgieter PD. Neurologic disease requiring long-term ventilation: the role of selective decontamination of the digestive tract in preventing nosocomial infection. Chest 1993; 104: 547-551.

52. Gastinne H, Wolff M, Delatour F, Faurisson F, Chevret S. A controlled trial in intensive care units of selective decontamination of the digestive tract with nonabsorbable antibiotics. The French Study Group on Selective Decontamination of the Digestive Tract. N Engl J Med 1992; 326: 594-599.

53. Martinez-Pellús AE, Merino P, Bru M, et al. Can selective digestive decontamination avoid the endotoxemia and cytokine activation promoted by cardiopulmonary bypass? Crit Care Med 1993; 21: 1684-1691.

54. Mahul Ph, Auboyer C, Jospe R, et al. Prevention of nosocomial pneumonia in intubated patients: respective role of mechanical subglottic secretions drainage and stress ulcer prophylaxis. Intensive Care Med 1992; 18: 2025.

55. Vallés J, Artigas A, Rello J, et al. Continuous aspiration of subglottic secretions in preventing ventilator-associated pneumonia. Ann Intern Med 1995; 122: 179-186. 